\title{
Direct Compression Properties of Microcrystalline Cellulose and Its Silicified Product
}

\author{
J. ALFA', M. A. ODENIYI ${ }^{2}$ AND K. T. JAIYEOBA ${ }^{2 *}$
}

\begin{abstract}
'Pharmaceutical Services Division, National Assembly Complex, Arms Zone, P.O. Box 5985, Garki, Abuja, Nigeria

${ }^{2}$ Department of Pharmaceutics \& Industrial Pharmacy, Faculty of Pharmacy, University of Ibadan, P.O. Box 14106, Ibadan, Nigeria
\end{abstract}

The influence of silicified microcrystalline cellulose (SMCC) on the flow, compaction and tableting properties of metronidazole powder was investigated. The study compared medium grades of both SMCC and standard microcrystalline cellulose (MCC) as direct compressible excipients. The bulk densities, Hausner quotient $\left(\mathrm{H}_{\mathrm{f}}\right)$, compressibility index $(\mathrm{C})$ and angle of repose of the formulations were evaluated. Compacts of the metronidazole containing different concentrations of SMCC or MCC $(10-30 \% \mathrm{w} / \mathrm{w})$ were made at compression forces of 20 to $30 \mathrm{KN}$ and evaluated for their physical characteristics. The flow behaviour of the drug was improved in the presence of SMCC. Formulations containing $25 \% \mathrm{w} / \mathrm{w}$ SMCC had lower $\mathrm{CI}$ and $\mathrm{H}_{\mathrm{f}}$ values than those made with $30 \% \mathrm{w} / \mathrm{w}$ MCC. The crushing strength of the compacts increased with concentration of the excipients at all the compression forces used. At similar concentrations of SMCC and MCC, compacts of the formulations containing SMCC exhibited higher crushing strengths. SMCC shows great promise as a filler-binder-disintegrant in direct compression of oral tablet formulations from both mechanical and economic viewpoints.

Keywords: Metronidazole, tablets, direct compression, Silicified Microcrystalline cellulose, microcrystalline cellulose.

\section{INTRODUCTION}

Direct compression has steadily gained ground in the pharmaceutical industry because of the cheap technical approach: a basic two-step process comprising of mixing and compressing [1]. It is however important that while desiring high production speed and low cost, the quality of the resulting tablet product is in no way compromised. A crucial step that could make or mar the success of direct compression processing is the selection of suitable direct compression vehicle(s). The excipients must fulfill certain requirements which include good binding and powder flow properties, compatibility with other excipients or drugs, a well designed particle size distribution to provide a favorable mixing condition and also the capacity to carry high amounts of active ingredient [2]. A good number of direct compression excipients are available commercially and it is the responsibility of the formulator to select the appropriate materials for optimum products.

Microcrystalline cellulose (MCC) is one of the most commonly used filler-binder in direct compression. Its popularity in direct compression is due to the extremely good bonding properties as a dry binder. It exhibits the highest capacity and compressibility of all known direct compression excipients. However, its flow properties are relatively poor and it exhibits low bulk densities. This has been attributed to its small particle size and particle shape. At low compression forces, stress relief is dominated by a slight elastic phase, which has been explained by its hollow microfibrillar structure [3]. At higher forces, it exhibits either further deformation or permanent deformation by non-specific plastic flow. This brings an extremely large surface area into close contact and facilitates hydrogen bond formation between the plastically deformed, adjacent cellulose particles. The high compatibility of 
MCC has been attributed to a relatively high propensity for plastic deformation, which enables large surfaces to come close to each other and a large number of bonds, mainly intermolecular forces, to be established between the particles [4]. The contribution of mechanical interlocking to the mechanical strength has also been suggested [5].

Silicified microcrystalline cellulose (SMCC) was introduced in 1996 and produced by co-processing $98 \%$ microcrystalline cellulose with $2 \%$ colloidal silicon dioxide (colloidal silica) [6,7]. The silicified microcrystalline cellulose product, patented as Prosolv ${ }^{\circledR}$ is expected to offer high synergistic flow and compaction qualities when compared with the conventional MCC grades. It has also been reported to offer high-speed direct compression tableting functional properties, superior compaction characteristics and excellent flow [8].

Drugs, which have poor flow and compressibility properties, require incorporation of appropriate adjuncts that would ensure desirable formulation characteristics. In this investigation, SMCC was employed as a means of enhancing the tableting behaviours of metronidazole powder, a poorly compressible powder with poor fluidity profiles. This study therefore set out to investigate the practicability of the use of SMCC and its effect on the formulation and tablet properties of metronidazole, using a similar grade of the traditional microcrystalline cellulose for comparison.

\section{EXPERIMENTAL}

\section{Materials}

Prosolv ${ }^{\mathrm{TM}} \mathrm{HD} \cdot 90$ (silicified microcrystalline cellulose), Emcocel ${ }^{\circledR} \quad 90 \quad$ (microcrystalline cellulose) (Penwest, Patterson, New York, USA) and metronidazole powder (Vision Pharmaceutical Co. Ltd. China) were used as obtained.

\section{Methods}

Binary mixtures of metronidazole and each excipient were prepared so as to contain 10,15, 20,25 or $30 \% \mathrm{w} / \mathrm{w}$ concentration of Silicified microcrystalline cellulose (SMCC) or microcrystalline cellulose (MCC). The excipient: drug mixture in each batch was blended for 5 mins in a planetary mixer. Batches of tablets were prepared at compression forces between $20-30 \mathrm{KN}$ using single punch tablet machine fitted with a punch of $12 \mathrm{~mm}$ diameter.

Bulk powder densities were determined using the Stamfpvolumeter Model STAV (JEF, Frankfurt, Germany). Hausner ratio was calculated from the ratio of the tapped bulk density $\left(\beta_{t}\right)$ to poured bulk density $\left(\beta_{b}\right)$ [9]. Compressibility index $(\mathrm{CI})$ and angle of repose $(\theta)$ were calculated from equations 1 and 2 respectively.

$$
\begin{aligned}
& \mathrm{CI}=100\left(\beta_{\mathrm{t}}-\beta_{\mathrm{b}}\right) / \beta_{\mathrm{t}} \ldots \ldots \ldots \ldots \ldots . \text { Equation } 1 \\
& \tan \theta=2 \mathrm{~h} / \mathrm{D} \ldots \ldots \ldots \ldots \ldots \ldots \ldots \ldots \ldots . \text { Equation } 2
\end{aligned}
$$

(where $\mathrm{h}$ and $\mathrm{D}$ represent measured height and diameter of the cone of powder respectively).

The flow rate was determined by measuring the time taken for a fixed quantity of powder to pass through the orifice of a Perspex flow tube. The crushing strength of the compacts was measured using the Erweka hardness tester Model DT (Erweka GMBH, Frankfurt, Germany). Friability was determined using the Erweka dual drum friabilator set to rotate at $25 \mathrm{rpm}$ for $4 \mathrm{mins}$. The Erweka disintegration tester Model EP4-4 (Erweka GMBH, Frankfurt, Germany) was used in determining disintegration time of the tablets by the British Pharmacopoeia method. In evaluating each of these parameters, determinations were made in triplicate and the average values recorded.

\section{RESULTS AND DISCUSSION}

The bulk density of a powder is dependent on particle packing and changes as the powder consolidates. A consolidated or tapped powder is likely to be more resistant to flow thus the ease with which a powder consolidates when subjected to controlled tapping can be used as an indirect measurement of powder flow.

The packing and flow characteristics of the formulations were determined and the results presented in Table 1. SMCC-drug mixtures show 
Table 1: Physical properties of metronidazole-excipient powder mix.

\begin{tabular}{llllllll}
\hline Excipient & $\%$ w/w & $\begin{array}{l}\text { Tapped bulk } \\
\text { density }\left(\boldsymbol{\beta}_{\mathfrak{t}}\right) \\
(\mathrm{g} / \mathrm{ml})\end{array}$ & $\begin{array}{l}\text { Poured bulk } \\
\text { density }\left(\boldsymbol{\beta}_{\mathrm{b}}\right) \\
(\mathrm{g} / \mathrm{ml})\end{array}$ & $\begin{array}{l}\text { Compressi- } \\
\text { bility index } \\
\mathbf{C l}(\%)\end{array}$ & $\begin{array}{l}\text { Hausner } \\
\text { ratio }\left(\mathrm{H}_{f}\right)\end{array}$ & $\begin{array}{l}\text { Angle of } \\
\text { Repose } \\
(\boldsymbol{\theta})\end{array}$ & $\begin{array}{l}\text { Flow Rate } \\
(\mathrm{g} / \mathrm{s})\end{array}$ \\
\hline Nil & - & 0.56 & 0.76 & 25.7 & 1.35 & & \\
MCC & 30 & 0.54 & 0.71 & 23.9 & 1.31 & 38 & 8.89 \\
SMCC & 20 & 0.60 & 0.78 & 23.0 & 1.31 & 37 & 10.0 \\
SMCC & 25 & 0.62 & 0.80 & 22.5 & 1.28 & 33.9 & 14.8 \\
\hline
\end{tabular}

greater bulk densities than mixtures containing regular $\mathrm{MCC}$, which can be explained by the improved flowability and packing properties [10]. The results show a decrease in Hausner ratio for SMCC as compared to MCC, even at lower concentrations of the former. This shows superior flow of SMCC over a corresponding grade of traditional MCC and is confirmed by the flow rate, angle of repose and compressibility index, which were significantly better. Further, adequate flow properties are crucial in the selection of excipients for direct compression tableting processes. Formulations which exhibit good flow characteristics have potentials of ensuring short production time and uniform product content [10].

The performance of metronidazole tablets formulated with $25 \%$ w/w of SMCC was compared with those containing $30 \% \mathrm{w} / \mathrm{w} \mathrm{MCC}$ and the results were presented in Table 2 . The effect of the concentration of the filler-binders on the crushing strength of metronidazole tablet formulation was evaluated and the results are presented in Figure 1. The drug that ordinarily has almost zero compressibility property was rendered compressible by the addition of either of the microcrystalline cellulose adjuncts. The crushing strength of compacts made with SMCC and a similar high-density grade of MCC increased with concentration of the direct-compression agents. The formulations containing SMCC however exhibited higher strength profiles at similar concentrations. At concentrations above $15 \%$ w/w, compacts containing SMCC had a strength advantage of about $45 \%$ over those formulated with MCC. It was found that compacts of metronidazole having crushing strength $4 \mathrm{KgF}$ and above could be obtained at $25 \mathrm{KN}$ force using SMCC at concentrations of $17 \%$ and above while similar results may be achieved with MCC at $30 \% \mathrm{w} / \mathrm{w}$ and above. The result shows that incorporation of a lower concentration of SMCC could match the use of a higher concentration of MCC with respect to compact strength of metronidazole tablets. This will lead to decreased tablet size and amount of excipients used and therefore to reduced cost of production.

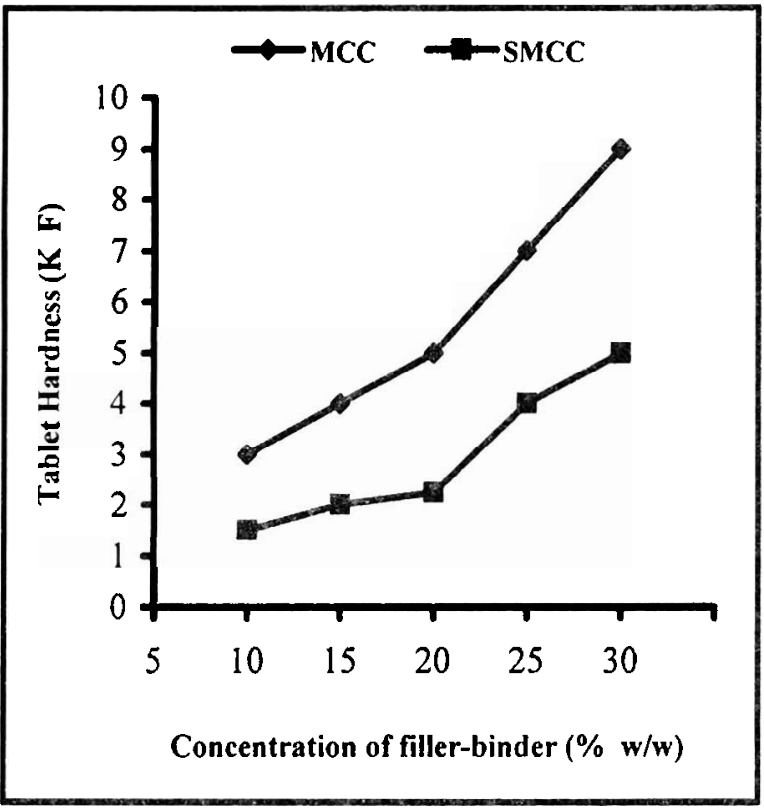

Figure 1: Effect of concentration of filler-binders on the strength of metronidazole tablets MCC: Microcrystalline Cellulose; SMCC Salicified Microcrystalline Cellulose

Further, the process of silicification while improving tablet strength, did not significantly 
affect the disintegration time at optimum compression pressure (Table 2). Both excipients produced tablets with similar disintegration time, though shorter for MCC. Kachrimanis et al. [11], observed extended disintegration times for compacts incorporating SMCC at a high relative humidity. This was attributed to probable saturation of the water uptake capacity of the excipient. The incorporated silicon dioxide is thought to act as a sink for moisture absorbed. However, in this study, the slightly lower disintegration time for $\mathrm{MCC}$ could be due to the higher quantity of the excipient in the formulation. It therefore seems that the silicification process does not adversely affect the inherent water uptake ability of microcrystalline cellulose in the presence of incorporated drug powder.

Table 2: Tablet properties of metronidazole formulations

\begin{tabular}{lll}
\hline \multirow{2}{*}{ Tablet property } & \multicolumn{2}{l}{ Filler-Binder } \\
\cline { 2 - 3 } & $\begin{array}{l}\text { SMCC (25\% } \\
\mathbf{w} / \mathbf{w})\end{array}$ & $\begin{array}{l}\text { MCC (30 } \\
\% \mathbf{w} / \mathbf{w})\end{array}$ \\
\hline Hardness (KgF) & 7.2 & 5.8 \\
Friability (\%) & 0.8 & 1.4 \\
Disintegration (s) & 60.0 & 55.0 \\
\hline
\end{tabular}

The results show that metronidazole formulations containing $30 \% \mathrm{w} / \mathrm{w}$ MCC or $25 \% \mathrm{w} / \mathrm{w}$ SMCC exhibited acceptable tableting properties including adequate crushing strength, excellent disintegration time and great potential to withstand rigors due to handling and packaging. The friability values were below $2 \%$ in the formulations studied.

\section{CONCLUSION}

The concentration of SMCC required to give satisfactory tablet quality in metronidazole formulations is much lower than that of MCC. The former also greatly imparted superior flow properties to metronidazole formulations when compared to the use of the latter. It would therefore appear that silicification of microcrystalline cellulose is of economic advantage over the use of conventional MCC in oral tablet formulations, since production cost will be reduced when the tabletting process involves reduced number and amount of materials in the formulation.

\section{REFERENCES}

[1] S. Mattsson and C. Nyström. Eur. J. Pharm. Sci. 10 (2000) 53-66.

[2] R.F Shangraw. In H.A. Lieberman, L. Lachman, and J.B Schwartz, (eds): Pharmaceutical Dosage Forms: Tablets. Vol 1, $2^{\text {nd }}$ Ed. Marcel Decker Incorporation. New York 1989, p 195.

[3] A. Wade and P.J. Weller. Handbook of Pharmaceutical Excipients. $2^{\text {nd }}$ ed. Washington, DC. American Pharmaceutical Association. 1994, pg. 45.

[4] K. Marshall, D. Sixsmith and N.G. Stanley-wood. J. Pharm. Pharmacol. (1972) 24, suppl., 138.

[5] P.G. Karehill and C. Nyström. Int. J. Pharm. 61 (1990) 251-260.

M.J. Tobyn, J.N. Staniforth and E.A. Hunter. Pharm. Res. 13 (1996) S198.

[7] JRS Pharma LP, Prosolv SMCC ${ }^{\circledR}$ : Silicified microcrystalline cellulose, Technical literature (2003).

[8] E.B. Sherwood, J.' Cobb, J. Becker, J. Zelenic, L. West, S. Edge and D.F Steel. Paper presented at the $19^{\text {th }}$ Pharmaceutical Technology conference, Baveno-Stresa, Italy, (2000); 207-210.

[9] H.H. Hausner. Int. J. Powder Met. 3 (1967) 7-13.

[10] T. Luukkonen, J.Schaefer, A.M. Helle'n and J. Juppo, Yliruusi. Int. J. Pharm. 188 (1999) 181-192.

[11] K. Kachrimanis, I. Nikolakakis and S. Malamataris. J. Pharm. Sci. 92 (2003) 1489-1501. 